\title{
Ketamine with propofol for endoscopic procedures
}

\author{
Anju Romina Bhalotra \\ Department of Anesthesiology, Maulana Azad Medical College and Associated Lok Nayak Hospital, New Delhi, \\ India
}

I read with interest the article by Singh et al. [1] comparing propofol alone and in combination with ketamine or fentanyl for sedation during endoscopic ultrasonography. The combination of propofol and ketamine is used to confer advantages such as hemodynamic stability, analgesia, a lower incidence of respiratory depression, and faster recovery. The authors suggest the use of $50 \mu \mathrm{g}$ fentanyl or $0.5 \mathrm{mg} / \mathrm{kg}$ ketamine in a single dose during endoscopic ultrasonography to reduce the dose of propofol required for sedation during the procedure. The dose of propofol administered was significantly higher in the propofol only group than in patients who received either fentanyl or ketamine as an adjuvant. However, in contrast to fentanyl, the use of ketamine prolonged the time to recovery $(\mathrm{P}<0.001)$. The ketamine-propofol combination, also called ketofol, has been used for procedural sedation in several studies in varying ratios. Wang et al. [2] studied the use of the propofol-ketamine combination in varying ratios of $2: 1,3: 1$, and $4: 1$ and compared it with the propofol-fentanyl combination and propofol alone. They found that ketofol was as safe and effective as the propofol-fentanyl combination. The level of sedation and recovery based on discharge times for the $3: 1$ and $4: 1$ mixtures of ketofol were comparable to those for the combination of propofol with fentanyl $50 \mu \mathrm{g}$ and propofol alone. The incidence of respiratory depression and post procedural drowsiness was

Corresponding author: Anju Romina Bhalotra, M.D.

Department of Anesthesiology, Maulana Azad Medical College and Associated Lok Nayak Hospital, A-1/59 Safdarjang Enclave, New Delhi 110029, India

Tel: 91-01126183684, Fax: 91-01126183684

Email:drakgk@yahoo.co.in

ORCID: https://orcid.org/0000-0003-0700-2941

Received: February 14, 2018.

Revised: February 27, 2018.

Accepted: March 18, 2018.

Korean J Anesthesiol 2018 August 71(4): 334-335

https://doi.org/10.4097/kja.d.18.00037 lower with a $4: 1$ ratio (160 $\mathrm{mg}$ propofol and $40 \mathrm{mg}$ ketamine) than with other ratios of ketofol. In another study, Gorji et al. [3] evaluated combinations of propofol with ketamine and fentanyl for endoscopic retrograde cholangiopancreatography. One group received ketamine $0.5 \mathrm{mg} / \mathrm{kg}$, while the other group was administered fentanyl 50-100 $\mu$ g. All patients received propofol $0.5 \mathrm{mg} / \mathrm{kg}$ followed by an infusion of $75 \mu \mathrm{g} / \mathrm{kg} / \mathrm{min}$. The level of sedation was equal in both groups $(\mathrm{P}>0.05)$, while analgesia was better with fentanyl compared to ketamine $(\mathrm{P}<0.05)$. Khajavi et al. [4] enrolled patients undergoing colonoscopy who were administered a combination of either fentanyl $0.5 \mu \mathrm{g} / \mathrm{kg}$ with propofol $0.5 \mathrm{mg} / \mathrm{kg}$ or ketamine $0.5 \mathrm{mg} / \mathrm{kg}$ with propofol 0.5 $\mathrm{mg} / \mathrm{kg}(1: 1 \mathrm{ratio})$. They found that patient satisfaction scores were significantly higher in the ketamine group. The level of sedation, hemodynamic status, oxygen saturation, incidence of nausea and vomiting, and recovery times were similar in both groups.

In the study by Singh et al. [1], the dose of propofol administered was significantly higher in the propofol alone group than in patients who received it in combination with ketamine or fentanyl. It seems self-evident that addition of either of these drugs would decrease the requirement for propofol. Patient hemodynamics and oxygenation were well maintained and comparable in all groups; however, the time to achieve a Post Anaesthesia Discharge Score (PADS) [5] of 10 was significantly higher in the ketamine group compared to the other two groups. Intraoperative sedation was titrated using the Ramsay sedation score. Perhaps anesthesia depth monitoring with BIS/entropy could have been used as a more objective measure of the level of sedation; frequent clinical assessment using the Ramsay score entails arousing the patient repeatedly. The ratio of propofol to ketamine used in the study was approximately $15: 1$; hence, it seems surprising that the time to achieve a PADS of 10 was delayed in the ketamine group compared to other groups. Besides, the components of the PADS [5] include vital signs, activity lev$\mathrm{el}$, nausea and vomiting, pain, and surgical bleeding. Hence, it is surprising that these parameters were affected by a relatively low

(c) This is an open-access article distributed under the terms of the Creative Commons Attribution Non-Commercial License (http://creativecommons.org/ licenses/by-nc/4.0/), which permits unrestricted non-commercial use, distribution, and reproduction in any medium, provided the original work is properly cited. 
dose of ketamine to significantly increase the PADS and lead to a longer time to discharge. Clarification is required regarding which of these parameters resulted in prolongation of the time to achieve a PADS of 10 and delayed recovery.

\section{References}

1. Singh SA, Prakash K, Sharma S, Dhakate G, Bhatia V. Comparison of propofol alone and in combination with ketamine or fentanyl for sedation in endoscopic ultrasonography. Korean J Anesthesiol 2018; 71: 43-7.

2. Wang Y, Jiang X, Pang L, Dong S, Feng Y, Prajapati SS, et al. A randomized double-blind controlled study of the efficacy of ketofol with propofol-fentanyl and propofol alone in termination of pregnancy. Afr J Pharm Pharmacol 2012; 6: 2510-4.

3. Bahrami Gorji F, Amri P, Shokri J, Alereza H, Bijani A. Sedative and analgesic effects of propofol-fentanyl versus propofol-ketamine during endoscopic retrograde cholangiopancreatography: a double-blind randomized clinical trial. Anesth Pain Med 2016; 6: e39835.

4. Khajavi M, Emami A, Etezadi F, Safari S, Sharifi A, Shariat Moharari R. Conscious sedation and analgesia in colonoscopy: ketamine/ propofol combination has superior patient satisfaction versus fentanyl/propofol. Anesth Pain Med 2013; 3: 208-13.

5. Chung F, Chan VW, Ong D. A post-anesthetic discharge scoring system for home readiness after ambulatory surgery. J Clin Anesth 1995; 7: $500-6$. 